\title{
A Lei dos Agrotóxicos: um estudo sobre a responsabilidade referida aos produtores rurais do interior do Estado de São Paulo
}

The Pesticides Law: a study on the responsibility referred to the farmers in the interior region of the state of São Paulo

La Ley de Plaguicidas: un estudio sobre la responsabilidad que se refiere a los productores rurales de la región interior del estado de Sao Paulo

Maurício Dias Marques

Mestrando em Agronegócio e Desenvolvimento, UNESP, Brasil, Membro do Grupo de Pesquisa em Educação Ambiental - PGEA, UNESP, Brasil mdmarques1985@gmail.com

\section{Sérgio Silva Braga Junior}

Professor Doutor, UNESP, Brasil. sergio@tupa.unesp.br

Dirceu da Silva

Professor Doutor, UNINOVE, Brasil. dirceuds@gmail.com 


\section{RESUMO}

O presente artigo procurou verificar como os produtores rurais do município de Tupã-SP estão cumprindo a responsabilidade prevista na legislação, quanto à logística reversa das embalagens vazias de agrotóxicos. Com base em pesquisa documental, para compreender a determinação da legislação, e em pesquisa bibliográfica sobre a logística reversa, foi realizada uma pesquisa de campo com aplicação de um questionário desenvolvido e validado seguindo as recomendações de DeVellis (2003) junto a 20 (vinte) produtores rurais do município, nos meses de abril e maio de 2015. O objetivo foi verificar como os produtores rurais percebem o procedimento da logística reversa das embalagens de agrotóxicos, proposta pela legislação brasileira para essas embalagens. Verificou-se que existe certa tendência dos produtores, em geral, de não cumprir o que é imposto pela legislação e uma das possíveis causas levantadas nesta pesquisa pode ser a falta de fiscalização do Poder Público.

PALAVRAS-CHAVE: Embalagens de agrotóxicos. Logística reversa. Legislação. 


\section{INTRODUÇÃO}

A produção agrícola sofreu grande impulso com utilização de defensivos agrícolas a partir da década de 1920 e, no Brasil, seu uso tornou-se intenso a partir da década de 1960. Isso gera grave problema de saúde pública, demandando a implantação de um sistema de vigilância da saúde de populações expostas a agrotóxicos (ORGANIZAÇÃO PAN-AMERICANA DA SAÚDE-OPAS / ORGANIZAÇÃO MUNDIAL DA SAÚDE-OMS (2010).

O Brasil está entre os principais consumidores mundiais de defensivos agrícolas, e a maior utilização dessas substâncias é na agricultura, principalmente nos sistemas de monocultura. Há discussões em torno do uso de defensivos agrícolas, tanto no que se refere a vantagens com respeito aos retornos econômicos e agronômicos que eles proporcionam ao produtor rural, como às desvantagens envolvidas nos campos da degradação ambiental e do risco à saúde humana. E, com respeito às embalagens, existem restrições legais relacionadas ao meio ambiente e aos fatores econômicos (SHIBAO; MOORI; SANTOS, 2010).

A Lei Federal n. ${ }^{\circ} 802$ de 11/07/89, regulamentada pelo Decreto n.o 98.816, no seu artigo 2, inciso I, define assim o termo "agrotóxicos": os produtos e os agentes de processos físicos, químicos ou biológicos destinados ao uso nos setores de produção, no armazenamento e beneficiamento de produtos agrícolas, nas pastagens, na proteção de florestas nativas ou implantadas e de outros ecossistemas e também em ambientes urbanos, hídricos e industriais, cuja finalidade seja alterar a composição da flora e da fauna, a fim de preservá-la da ação danosa de seres vivos considerados nocivos, e, substâncias e produtos empregados como desfolhantes, dessecantes, estimuladores e inibidores do crescimento.

Segundo a OPAS/OMS ( 2010), os produtos comercializados abrangem cerca de 300 princípios ativos em duas mil formulações comerciais diferentes no Brasil, cuja classificação pode-se resumir em: a) Inseticidas (possuem ação de combate a insetos, larvas e formigas); b) Fungicidas (combatem fungos); c) Herbicidas (combatem ervas daninhas); d) Raticidas (combate a roedores); e) Acaricidas (combate a ácaros diversos); f) Nematicidas (combate a nematóides); g) Molusquicidas (combate a moluscos, basicamente o caramujo da esquistossomose; h) Fundgantes (combate a insetos e bactérias).

Para minimizar o problema em torno das embalagens desses produtos químicos, a legislação brasileira trata do descarte de embalagens vazias de defensivos. A Política Nacional de Resíduos Sólidos (Lei 12.305/2010) estabeleceu como instrumento de desenvolvimento econômico e social a implantação de sistemas de logística reversa, consistente num conjunto de ações, procedimentos e meios destinados a viabilizar a coleta e a restituição dos resíduos sólidos ao setor empresarial, para aproveitamento em seu ciclo ou em outros ciclos produtivos, ou para destinação final ambientalmente adequada, conforme art. 3ำ XII da Lei. A aplicação da logística reversa requer integração entre União, Estados, Municípios e particulares, que irão somar investimentos e esforços com a preocupação da conservação do meio ambiente.

A Logística Reversa do Pós-Consumo (aplicada no caso das embalagens de agrotóxicos), abrange os bens que, após serem produzidos e utilizados, passam a ser de pós-consumo, e devido a isso os mesmos podem ser enviados a destinos finais tradicionais, como por exemplo, incineração e 
aterros sanitários, ou também podem retornar ao ciclo produtivo, através da reciclagem ou reuso (LEITE, 2003).

A destinação final das embalagens vazias exige procedimento complexo e requer a participação efetiva de todos os agentes envolvidos na fabricação, comercialização, utilização, licenciamento, fiscalização e monitoramento das atividades relacionadas com manuseio, transporte, armazenamento e processamento dessas embalagens. O processo de logística reversa tem oportunidade para a sistematização dos fluxos de resíduos, bens e produtos descartados, seja pelo fim de sua vida útil, seja por obsolescência tecnológica e o seu reaproveitamento, dentro ou fora da cadeia produtiva de origem, contribuindo dessa forma para redução do uso de recursos naturais e dos demais impactos ambientais. É ferramenta organizacional que tem o intuito de viabilizar técnica e economicamente as cadeias reversas, de forma a contribuir para a promoção da sustentabilidade de uma cadeia produtiva (SHIBAO, MOORI, SANTOS, 2010).

\section{PROBLEMA E OBJETIVO}

A problemática é como a legislação que implantou e regulamentou os procedimentos da logística reversa das embalagens de agrotóxicos está sendo comprida. No caso deste estudo, como a logística reversa está sendo iniciada pelos produtores rurais no município de Tupã?

Com o objetivo de verificar como os produtores rurais percebem o procedimento da logística reversa das embalagens de agrotóxicos no primeiro elo da cadeia proposto pela legislação brasileira para estas embalagens, foi realizada uma pesquisa de campo junto a 20 (vinte) produtores rurais do município de Tupã/SP, nos meses de abril e maio de 2015, com utilização de formulário com 19 questões, para verificar como está sendo cumprida a legislação.

\section{FUNDAMENTAÇÃO TEÓRICA}

Em virtude do objetivo proposto foram buscados conceitos, como a base agrícola de Tupã, a legislação relacionada às embalagens vazias de agrotóxicos e a logística reversa.

\subsection{A AGRICULTURA EM TUPÃ}

A agricultura no município de Tupã apresenta produção diversificada de alimentos e é responsável por assumir importante destaque na segurança alimentar regional.

Segundo dados do IBGE (2014), o município de Tupã/SP, tinha em 2014 uma população estimada em 65.596 habitantes, área territorial de 628.126 km2. Sua produção agrícola em 2013 desdobrava-se em lavoura temporária: amendoim, arroz, cana-de-açúcar, feijão, mandioca, melancia, milho, sorgo e tomate; e em lavoura permanente: abacate, banana, borracha, café, cocoda-bahia, laranja, mamão, manga e tangerina.

A agricultura familiar possui importante papel no município de Tupã por contribuir com a diversidade de alimentos, mas sem dúvida, para elevar a produção, grande parte dos agricultores 
utilizam insumos químicos sintéticos e se enquadram na obrigatoriedade da devolução de embalagens de agroquímicos, como ficou evidenciado pelos produtores entrevistados.

A agricultura familiar é fonte fornecedora de alimentos in natura para o consumo direto e de matéria-prima para as agroindústrias de processamento. Uma única e pequena unidade produtiva da agricultura familiar pode produzir e fornecer uma infinidade de produtos (TEDESCO, 2001). Porém a grande maioria dos agricultores familiares ainda estão inseridos num sistema de produção convencional, com uso de insumos químicos sintéticos. Poucas unidades de produção priorizam o sistema agroecológico ou orgânico.

Para regulamentar a aplicação desses insumos químicos, notadamente os agrotóxicos e o destino final de suas embalagens, a legislação brasileira traça regras que devem ser obedecidas.

\subsection{LEGISLAÇÃO}

Há uma legislação brasileira específica para o tratamento que deve ser dado às embalagens de agrotóxicos até o retorno das embalagens vazias às indústrias por meio da logística reversa. Marques, Braga Junior e Cataneo (2015), apresentam uma síntese da legislação sobre as embalagens de agrotóxicos e demonstram que, ao longo do tempo, as discussões avançaram em aplicabilidade e abrangência.

De toda essa legislação, ressalta-se o estabelecimento de responsabilidades compartilhadas a todos os agentes que participam do processo de retorno das embalagens vazias de agrotóxicos, por meio da logística reversa. Há responsabilidades para os agricultores, que utilizam o agrotóxico em suas lavouras; há responsabilidades para o comerciante, revendedor do agrotóxico; há responsabilidades para as Unidades de Recebimento controladas pelo INPEV (Instituto Nacional de Processamento de Embalagens Vazias); há responsabilidades para as indústrias fabricantes dos agrotóxicos e há responsabilidades para o Poder Público.

Interessa a este a este estudo as responsabilidades impostas pela legislação aos agricultores, considerados como usuários ou utilizadores dos produtos. Segundo comentários de Cometti (2009), Melo et al. (2012), Cantos, Miranda e Licco (2008), Grutzmacher et al. (2006) e Faria e Pereira (2012), seriam estas as responsabilidades dos agricultores:

- preparar as embalagens vazias para devolvê-las nas unidades de recebimento (embalagens rígidas laváveis: efetuar a tríplice lavagem ou lavagem sob pressão; inutilizar, perfurando, para evitar o reaproveitamento; embalagens rígidas não laváveis: mantê-las intactas, adequadamente tampadas e sem vazamento; embalagens flexíveis contaminadas: acondicioná-las em sacos plásticos padronizados);

- armazenar, temporariamente, as embalagens vazias na propriedade em local adequado;

- transportar e devolver as embalagens vazias, com suas respectivas tampas, no estabelecimento onde foi adquirido o produto ou na unidade de recebimento indicada na nota fiscal, no prazo de até um ano contado da data de sua compra;

- manter em seu poder os comprovantes de entrega das embalagens e a nota fiscal de compra do produto por um ano.

E, essas responsabilidades atribuídas ao produtor rural são cumpridas por meio da iniciação do processo da Logística Reversa. 


\subsection{LOGÍSTICA REVERSA}

A logística reversa, estabelecida pela PNRS (Política Nacional de Resíduos Sólidos), Lei 12.305/2010, é um instrumento eficaz no retorno das embalagens de agrotóxicos, aliada à preocupação com o meio ambiente. Tem por princípio o resgate de bens materiais que seriam lançados sem qualquer cuidado na natureza, trazendo-os de volta à cadeia de distribuição da empresa. Foi estabelecida como instrumento de desenvolvimento econômico e social, imputando a responsabilidade do pós-consumo aos fabricantes, importadores, distribuidores, comerciantes e consumidores (MOURÃO e SEO, 2012).

Conforme Victor (2010), uma das principais atribuições trazidas pela lei 12.305/10 (Política Nacional de Resíduos Sólidos) é a logística reversa, consistente num conjunto de ações, procedimentos e meios destinados a viabilizar a coleta e a restituição dos resíduos sólidos ao setor empresarial, para aproveitamento em seu ciclo ou em outros ciclos produtivos, ou para destinação final ambientalmente adequada, conforme art. 3ํ, XII da Lei. A logística reversa torna-se aplicável, tanto sob o aspecto empresarial, quanto sob a análise constitucional, necessitando de integração entre União, Estados, Municípios e particulares, somando-se investimentos e esforços com preocupação da conservação do meio ambiente.

Novas abordagens foram sendo inseridas no conceito da logística reversa, englobando retorno dos produtos, reciclagem, ações para substituição e/ou reutilização de materiais, disposição final de resíduos, reparação, reaproveitamento e remanufatura de materiais, incluindo-se também a questão da eficiência ambiental (MOTTA, 2013)

Braga Junior, Merlo e Nagano (2009) explicam que a logística reversa se apresenta como a área da logística empresarial que planeja, opera e controla o fluxo e as informações logísticas do retorno dos bens de pós-venda e de pós-consumo ao ciclo de negócios ou ao ciclo produtivo, agregando-Ihes valores: econômico, ecológico, legal, logístico, de imagem corporativa, e outros.

O retorno das embalagens vazias de agrotóxicos enquadra-se na Logística Reserva de PósConsumo, que é a área que equaciona e operacionaliza o fluxo físico e as informações correspondentes de bens de pós-consumo descartados pela sociedade em geral, que retornam ao ciclo de negócios ou ao ciclo produtivo por meio de canais de distribuição reversos específicos. Bens de pós-consumo são os produtos em fim de vida útil ou usados com possibilidade de utilização e os resíduos industriais em geral. Esse retorno tem por fim agregar valor a um produto logístico constituído por bens inservíveis ao proprietário original, ou que ainda possuam condições de utilização, por produtos descartados por terem atingido o fim de vida útil e por resíduos industriais. Estes produtos de pós-consumo poderão se originar de bens duráveis ou descartáveis e fluírem por canais reversos de Reuso, Desmanche, Reciclagem até a destinação final (BRAGA JUNIOR e PINHEIRO, 2014).

No caso do recolhimento das embalagens de defensivos agrícolas utilizados nas plantações, exige-se uma cooperação que depende diretamente dos produtores rurais, que fazem parte de um elo da cadeia agrícola, como destacado por Inpev (2010). "A cooperação entre os elos da cadeia agrícola pode ser observada pelos fluxos de entrega ou logística convencional (matéria- 
prima, manufatura, distribuição e varejo) e pelos fluxos de recolhimento ou logística reversa (coleta, transporte, desmantelamento e decomposição" (LADEIRA, MAEHLER, NASCIMENTO, 2012, p. 158).

Noi mesmo sentido, Carboni; Sato e Moori (2005) argumentam que o processo da logística reversa das embalagens vazias inicia-se no agricultor, que tem a obrigação legal de efetuar, nas embalagens, uma tríplice lavagem ou lavagem sob pressão e devolvê-las no prazo de um ano após a compra ou de seis meses após o vencimento do produto. A lavagem sob pressão é utilizada no caso de embalagens rígidas e metálicas, enquanto que as flexíveis (sacos de papel, aluminizados e polietileno de baixa densidade) tem como destino a incineração.

De acordo com Boldrin et al. (2007, p.36), as seguintes etapas devem ser seguidas para que a coleta de embalagens vazias de agrotóxicos no campo tenha êxito: produtor: "produtor $\rightarrow$ incentivos à devolução $\rightarrow$ tríplice lavagem $\rightarrow$ transporte da zona rural até o centro coletor $\rightarrow$ recebimento no centro coletor $\rightarrow$ armazenamento neste centro até determinado nível de estoque $\rightarrow$ recolhimento por parte da indústria para ser dada a destinação final".

\section{METODOLOGIA}

Trata-se de uma pesquisa de natureza exploratória que prioriza desenvolver, esclarecer e entender conceitos e ideias visando a formulação de problemas mais precisos, envolvendo levantamento bibliográfico e documental (HAIR et al., 2005). Justifica-se a escolha deste método de pesquisa devido à temática da logística reversa e da educação ambiental possuírem lacunas no âmbito rural. Quanto à coleta de dados, além do levantamento bibliográfico e documental, foi realizada uma pesquisa a campo com 17 questões fechadas (P1 a P17) utilizando escala Likert de cinco pontos e duas questões abertas (P18 e P19) para observar as responsabilidades dos produtores rurais constantes nos parágrafos 2o e 4o da Lei dos Agrotóxicos (Lei 7.802/1989) e no artigo 53 do Decreto 4.074/2002.

Seguindo as recomendações de DeVellis (2003), para avaliar e realizar a validação de fase da escala apresentada no quadro 1 a mesma foi analisada por 10 especialistas da área do direito ambiental e de logística reversa que contribuíram para ajustar as frases (avaliação) e analisar se as mesmas se encaixavam no construto proposto pela pesquisa (validação de fase) e se atendiam a Lei dos Agrotóxicos. 0 formulário foi aplicado a 20 produtores rurais, não identificados para manter 0 anonimato, durante os meses de abril e maio de 2015.

Para análise dos dados foi utilizado o software SPSS 22.0 para os testes de frequência, analise fatorial exploratória (AFE) e classificação dos casos. Para análise dos constructos foi gerada uma reta de regressão linear resultado do processamento dos dados feito pelo software para cada um dos constructos. Explicando melhor, usou-se a técnica de AFE, com opção de fator único apenas para gerar os valores de $\hat{Y}$ (valores ajustados sobre o eixo y correspondentes à reta de regressão gerada). Esse procedimento foi realizado três vezes (para cada um dos constructos do quadro 1), obtendo-se também três classificações dos casos (ou empresas respondentes) em cada um dos três fatores (PESTANA e GAGEIRO, 2000). 
Quadro 1 - Escala utilizada na pesquisa - já agrupada por fatores.

\begin{tabular}{|c|c|c|}
\hline Fatores & № & Itens \\
\hline \multirow{7}{*}{$\begin{array}{l}\text { A - Efetuar a devolução } \\
\text { das embalagens vazias, } \\
\text { de acordo com as } \\
\text { instruções recebidas, } \\
\text { no estabelecimento } \\
\text { onde adquiriu ou nos } \\
\text { postos de } \\
\text { recolhimento. }\end{array}$} & $\mathrm{P}-01$ & $\begin{array}{l}\text { Sempre sou informado que existe a obrigatoriedade de devolver as embalagens } \\
\text { vazias de defensivos agrícolas. }\end{array}$ \\
\hline & $\mathrm{P}-02$ & $\begin{array}{l}\text { Costumo ler as instruções das bulas e rótulos dos defensivos agrícolas antes de } \\
\text { utilizar. }\end{array}$ \\
\hline & P-03 & $\begin{array}{l}\text { Costumo ler as instruções das bulas e rótulos dos defensivos agrícolas sobre da } \\
\text { devolução das embalagens. }\end{array}$ \\
\hline & $\mathrm{P}-08$ & Sempre devolvo as embalagens no endereço indicado na nota fiscal de compra. \\
\hline & P-09 & Quando tenho defensivo agrícola vencido costumo devolver. \\
\hline & P-10 & Sempre pago custos de transporte das embalagens até ao posto de coleta. \\
\hline & P-12 & $\begin{array}{l}\text { Sempre faço a devolução das embalagens vazias de defensivo agrícola nos } \\
\text { revendedores onde compro. }\end{array}$ \\
\hline \multirow{5}{*}{$\begin{array}{l}\text { B - Efetuar a tríplice } \\
\text { lavagem das } \\
\text { embalagens vazias, } \\
\text { preparo necessário e } \\
\text { armazenamento prévio } \\
\text { na propriedade rural. }\end{array}$} & $\mathrm{P}-04$ & $\begin{array}{l}\text { Fui informado da necessidade de preparar as embalagens para o descarte } \\
\text { correto. }\end{array}$ \\
\hline & P-05 & $\begin{array}{l}\text { Fui informado que preciso mantê-las armazenadas, temporariamente, em local } \\
\text { adequado em minha propriedade. }\end{array}$ \\
\hline & P-06 & $\begin{array}{l}\text { Na compra, são dados os procedimentos de lavagem, acondicionamento, } \\
\text { armazenamento, transporte e devolução das embalagens. }\end{array}$ \\
\hline & P-07 & Costumo inutilizar a embalagem logo após fazer a tríplice lavagem. \\
\hline & $\mathrm{P}-17$ & Faço a tríplice lavagem quando prevista nas instruções das bulas. \\
\hline \multirow{5}{*}{$\begin{array}{l}\text { C-Manter à disposição } \\
\text { dos órgãos } \\
\text { fiscalizadores os } \\
\text { comprovantes de } \\
\text { devolução das } \\
\text { embalagens vazias. }\end{array}$} & P-11 & $\begin{array}{l}\text { O Posto de Coleta sempre entrega um comprovante de recebimento das } \\
\text { embalagens. }\end{array}$ \\
\hline & P-13 & $\begin{array}{l}\text { Mantenho arquivado para efeito de fiscalização, as notas fiscais de compras e os } \\
\text { comprovantes de devolução das embalagens vazias. }\end{array}$ \\
\hline & P-14 & $\begin{array}{l}\text { Quando realizo uma nova compra de defensivo agrícola, sou cobrado pelo } \\
\text { revendedor sobre as embalagens vazias da ultima compra. }\end{array}$ \\
\hline & P-15 & $\begin{array}{l}\text { Recebo com regularidade fiscalização sobre o armazenamento, transporte e } \\
\text { devolução das embalagens vazias de defensivos agrícolas. }\end{array}$ \\
\hline & P-16 & $\begin{array}{l}\text { Tenho conhecimento das penalidades aplicadas pela destinação inadequada das } \\
\text { embalagens vazias. }\end{array}$ \\
\hline
\end{tabular}

Fonte: os autores

Os valores calculados representam o conjunto de respostas fornecidas por cada produtor e que está compondo cada constructo. Na sequência, foi possível avaliar e classificar os produtores em três categorias: com tendência positiva, indiferença e tendência negativa de percepção e aplicação da Lei dos Agrotóxicos.

Quanto a abordagem, a pesquisa foi desenvolvida sob uma perspectiva quali-quantitativa. A qualitativa busca analisar e interpretar aspectos profundos, descrever a complexidade do comportamento humano, com riquezas de detalhes das investigações, hábitos, ações, tendências comportamentais, entre outros aspectos peculiares. A quantitativa vale-se de amostras e de informações numéricas para estudos com maior objetividade (HAIR et al., 2005).

\section{ANÁLISE DOS RESULTADOS}

Os formulários aplicados aos produtores rurais trazem informações sobre o início do processo da logística reversa das embalagens vazias de agrotóxicos em Tupã/SP, uma vez que a legislação determina que esse início se dá junto aos produtores rurais que utilizam o agrotóxico em suas lavouras. As informações obtidas podem ser analisadas como segue: 


\section{Classificação dos produtores participantes da pesquisa}

Como base informativa sobre a categoria dos produtores consultados, respondentes do formulário, foram tomados três elementos: tipo de cultura, tamanho da área e o tempo em que produz na área. Com isso são descritas variáveis como o tamanho do produtor em área (pequeno, médio ou grande), as culturas agrícolas predominantes e sua experiência, como se verá:

\section{Grupos de Cultivo em que se enquadram os respondentes}

A maior parte deles pratica a horticultura (45\%), seguindo-se ocupações com lavouras permanentes e lavouras temporárias, como se verifica na tabela 1.

Tabela 1 - Grupos de Cultivo.

\begin{tabular}{lcccc}
\hline & Frequência & Porcentagem & $\begin{array}{c}\text { Porcentagem } \\
\text { válida }\end{array}$ & $\begin{array}{c}\text { Porcentagem } \\
\text { acumulativa }\end{array}$ \\
\hline produção de lavouras temporárias & 5 & 25,0 & 25,0 & 25,0 \\
horticultura e floricultura & 9 & 45,0 & 45,0 & 70,0 \\
produção de lavouras & 6 & 30,0 & 30,0 & 100,0 \\
permanentes & $\mathbf{2 0}$ & $\mathbf{1 0 0 , 0}$ & $\mathbf{1 0 0 , 0}$ & \\
Total & & & &
\end{tabular}

Fonte: os autores

Segmentação da área produtiva ocupada pelos respondentes, em hectares

A maior parte deles ocupa uma área entre 2 a 5 hectares (35\%), seguidos por aqueles que ocupam área menor de até 1 hectare (15\%), e com boa distribuição entre os demais, como se verifica na tabela 2.

Tabela 2 - Segmentação da área explorada.

\begin{tabular}{lcccc}
\hline & Frequência & Porcentagem & $\begin{array}{c}\text { Porcentagem } \\
\text { válida }\end{array}$ & $\begin{array}{c}\text { Porcentagem } \\
\text { acumulativa }\end{array}$ \\
\hline Maior de 0 a menos de 1 há & 3 & 15,0 & 15,0 & 15,0 \\
De1 a menos de 2 ha & 1 & 5,0 & 5,0 & 20,0 \\
De2 a menos de 5 ha & 7 & 35,0 & 35,0 & 55,0 \\
De 5 a menos de 10 ha & 1 & 5,0 & 5,0 & 60,0 \\
De 10 a menos de 20 ha & 2 & 10,0 & 10,0 & 70,0 \\
De 20 a menos de 50 ha & 2 & 10,0 & 10,0 & 80,0 \\
De50 a menos de 100 ha & 1 & 5,0 & 5,0 & 85,0 \\
De 100 a menos de 200 ha & 1 & 5,0 & 5,0 & 90,0 \\
De 200 a menos de 500 ha & 2 & 10,0 & 10,0 & 100,0 \\
Total & $\mathbf{2 0}$ & $\mathbf{1 0 0 , 0}$ & $\mathbf{1 0 0 , 0}$ & \\
\hline
\end{tabular}

Fonte: os autores 


\section{Tempo que os respondentes produzem na área}

A maior parte deles pratica sua atividade agrícola no período entre 5 a 10 anos (40\%), seguidos pelos que ocupam a área entre 1 a 5 anos (20\%), até 1 ano (15\%) e os demais praticam a agricultura a mais de 10 anos, como se pode verificar na tabela 3 .

Tabela 3 - Tempo que produz na área explorada.

\begin{tabular}{lcccc}
\hline & Frequência & Porcentagem & $\begin{array}{c}\text { Porcentagem } \\
\text { válida }\end{array}$ & $\begin{array}{c}\text { Porcentagem } \\
\text { acumulativa }\end{array}$ \\
\hline Até 1 ano & 3 & 15,0 & 15,0 & 15,0 \\
Mais de 1 a 5 anos & 4 & 20,0 & 20,0 & 35,0 \\
Mais de 5 a 10 anos & 8 & 40,0 & 40,0 & 75,0 \\
Mais de 10 a 15 anos & 2 & 10,0 & 10,0 & 85,0 \\
Mais de 15 a 20 anos & 2 & 10,0 & 10,0 & 95,0 \\
Mais de 20 anos & 1 & 5,0 & 5,0 & 100,0 \\
Total & $\mathbf{2 0}$ & $\mathbf{1 0 0 , 0}$ & $\mathbf{1 0 0 , 0}$ & \\
\hline
\end{tabular}

Fonte: os autores

Todas essas configurações demonstram que a amostra tem uma abrangência variável, atingindo produtores rurais em diversas situações. E, as respostas dadas aos quesitos, cuja análise se fará adiante, mostram que as diferenças de área, cultura ou tempo de produção não implicam no acatamento da responsabilidade desses produtores rurais frente ao requerido na legislação quanto ao retorno das embalagens vazias de agrotóxicos.

\section{Análise das questões fechadas.}

Para que os grupos apresentados no quadro 1 fossem analisados, foi gerada uma reta de regressão para cada um deles, utilizando as questões que compõem cada qual e que constam do formulário aplicado. Teve como propósito uma classificação em negativo (1), indiferente (2) e positivo (3), o que indica a tendência mais descritiva do comportamento desses agricultores.

A - Efetuar a devolução das embalagens vazias, de acordo com as instruções recebidas, no estabelecimento onde adquiriu ou nos postos de recolhimento.

A tendência dos produtores rurais respondentes a efetuar a devolução das embalagens vazias, de acordo com as instruções recebidas quer oralmente, quer por meio da leitura do rótulo ou da bula, está empatada com a tendência dos indiferentes que tanto podem como não efetuar essa devolução, sendo cada situação da ordem de $35 \%$. E os que tendem a não efetuar a devolução estão percentualmente enquadrados em $30 \%$, como se pode ver na tabela 4 . 
Tabela 4 - Devolução das embalagens vazias conforme instruções recebidas.

\begin{tabular}{lrrrr}
\hline & Frequência & Porcentagem & $\begin{array}{c}\text { Porcentagem } \\
\text { válida }\end{array}$ & $\begin{array}{r}\text { Porcentagem } \\
\text { acumulativa }\end{array}$ \\
\hline $\begin{array}{l}\text { Tende a não efetuar a devolução } \\
\text { das embalagens vazias }\end{array}$ & 6 & 30,0 & 30,0 & 30,0 \\
$\begin{array}{l}\text { Pode ou não efetuar a devolução } \\
\text { das embalagens vazias }\end{array}$ & 7 & 35,0 & 35,0 & 65,0 \\
$\begin{array}{l}\text { Tende a efetuar a devolução das } \\
\text { embalagens vazias }\end{array}$ & 7 & 35,0 & 35,0 & 100,0 \\
Total & $\mathbf{2 0}$ & $\mathbf{1 0 0 , 0}$ & $\mathbf{1 0 0 , 0}$ & \\
\hline
\end{tabular}

Fonte: os autores

B - Efetuar a tríplice lavagem das embalagens vazias, preparo necessário e armazenamento prévio na propriedade rural.

A tendência dos produtores rurais respondentes é a mesma do grupo anterior, verificando-se que os que tendem a proceder à lavagem, preparo e armazenagem temporária para a devolução das embalagens vazias está empatada com a tendência dos que são indiferentes, que tanto podem como não fazer a lavagem, preparo e armazenagem das embalagens, ficando cada um com $35 \%$. Os que tendem a não efetuar o preparo e armazenamento temporário das embalagens para devolução chega a $30 \%$, como se verifica na tabela 5 .

Tabela 5 - Tríplice lavagem, preparo e armazenamento prévio das embalagens vazias.

\begin{tabular}{|c|c|c|c|c|}
\hline & Frequência & Porcentagem & $\begin{array}{l}\text { Porcentagem } \\
\text { válida }\end{array}$ & $\begin{array}{l}\text { Porcentagem } \\
\text { acumulativa }\end{array}$ \\
\hline $\begin{array}{l}\text { Tende a não efetuar a tríplice } \\
\text { lavagem, preparar e armazenar } \\
\text { corretamente as embalagens }\end{array}$ & 6 & 30,0 & 30,0 & 30,0 \\
\hline $\begin{array}{l}\text { Pode ou não efetuar a tríplice } \\
\text { lavagem, preparar e armazenar } \\
\text { corretamente as embalagens }\end{array}$ & 7 & 35,0 & 35,0 & 65,0 \\
\hline $\begin{array}{l}\text { Tende a efetuar a tríplice lavagem, } \\
\text { preparar e armazenar } \\
\text { corretamente as embalagens }\end{array}$ & 7 & 35,0 & 35,0 & 100,0 \\
\hline Total & 20 & 100,0 & 100,0 & \\
\hline
\end{tabular}

Fonte: os autores

C - Manter à disposição dos órgãos fiscalizadores os comprovantes de devolução das embalagens vazias.

A tendência aqui representada é a mesma dos Grupos A e B, que verificam a disposição dos respondentes em efetuar a devolução das embalagens vazias. Então, os que têm a tendência de manter os comprovantes da devolução das embalagens para efeito de fiscalização são iguais àqueles que são indiferentes, que podem manter ou não, ficando cada situação na ordem de $35 \%$. Já os que tendem a não manter os comprovantes à disposição da fiscalização representam $30 \%$, como pode ser visto na tabela 6 . 
Tabela 6 - Predisposição a manter à disposição da fiscalização os comprovantes de devolução das embalagens vazias.

\begin{tabular}{|c|c|c|c|c|}
\hline & Frequência & Porcentagem & $\begin{array}{c}\text { Porcentagem } \\
\text { válida }\end{array}$ & $\begin{array}{l}\text { Porcentagem } \\
\text { acumulativa }\end{array}$ \\
\hline $\begin{array}{l}\text { Tende a não manter à disposição da } \\
\text { fiscalização os comprovantes de devolução } \\
\text { das embalagens }\end{array}$ & o & 30,0 & 30,0 & 30,0 \\
\hline $\begin{array}{l}\text { Pode ou não manter à disposição da } \\
\text { fiscalização os comprovantes de devolução } \\
\text { das embalagens }\end{array}$ & o & 35,0 & 35,0 & 65,0 \\
\hline $\begin{array}{l}\text { Tende a manter à disposição da fiscalização } \\
\text { os comprovantes de devolução das } \\
\text { embalagens }\end{array}$ & ăo & 35,0 & 35,0 & 100,0 \\
\hline Total & 20 & 100,0 & 100,0 & \\
\hline
\end{tabular}

Fonte: os autores

Esse conjunto de análises dos Grupos de questões A, B e C, leva a uma só conclusão. Dos 20 produtores rurais respondentes do formulário de pesquisa, 7 (sete) têm a tendência de cumprir a legislação (35\%), 7 (sete) são indiferentes, ao mesmo tempo em que podem se interessar a cumprir podem também não interessar (35\%) , e o restante, 6 (seis), são tendentes a não cumprir o que determina a legislação consoante à sua responsabilidade como iniciantes do processo de logística reversa das embalagens vazias de agrotóxicos (30\%).

\section{Análise das questões abertas, quanto ao tempo de devolução e onde é jogada a água da lavagem.}

Para esses quesitos foram surpreendentes as respostas, já que quanto a água da lavagem, a totalidade dos produtores respondentes afirmaram retornar a água no tanque ou bomba, para aproveitar ao máximo o produto e quanto à devolução: $30 \%$ não devolve, $15 \%$ nunca devolveu, $45 \%$ varia no tempo de devolução, não se recordando quando foi a última devolução efetuada, e apenas 2 produtores afirmaram fazer a devolução, um no prazo correto de 1 ano e o outro em prazo superior, como se pode ver na tabela 7.

Tabela 7 - Espaço de tempo que costuma devolver as embalagens vazias de agrotóxicos

\begin{tabular}{lrrrr}
\hline & Frequência & Porcentagem & $\begin{array}{c}\text { Porcentagem } \\
\text { válida }\end{array}$ & $\begin{array}{c}\text { Porcentagem } \\
\text { acumulativa }\end{array}$ \\
\hline 1 ano & 1 & 5,0 & 5,0 & 5,0 \\
2 anos & 1 & 5,0 & 5,0 & 10,0 \\
não devolve & 6 & 30,0 & 30,0 & 40,0 \\
nunca & 3 & 15,0 & 15,0 & 55,0 \\
varia & 9 & 45,0 & 45,0 & 100,0 \\
Total & $\mathbf{2 0}$ & $\mathbf{1 0 0 , 0}$ & $\mathbf{1 0 0 , 0}$ & \\
\hline
\end{tabular}

Fonte: os autores. 
De todas as análises efetuadas, observa-se que a classificação dos produtores pesquisados quanto aos grupos de cultivo, se cultura temporária, horticultura ou cultura permanente e quanto à segmentação da área produtiva tanto em hectares quanto em tempo de produção não tem relação direta com as respostas dadas às questões sobre o cumprimento da legislação. Estas permaneceram num mesmo posicionamento independendo daquelas variáveis.

Relativamente à questão aberta "de quanto em quanto tempo faço a devolução das embalagens", comparativamente ao Grupo A, percebe-se a caracterização da decisão de não devolver por parte de 06 (seis) dos respondentes (30\%), enquanto que os demais ficam na tendência do indiferentismo ou da não devolução.

Relativamente à questão aberta "onde é jogada a água da lavagem", comparativamente ao Grupo $B$, percebe-se que nesse grupo a análise leva em conta a lavagem, o preparo e o armazenamento temporário dentro da propriedade rural, razão pela qual certamente aparecem aqueles que embora efetuem a lavagem porque lhes interessa do ponto de vista econômico, não tendem a dar o devido cuidado no preparo e armazenamento prévio para posterior devolução, resultando daí nessa tendência o percentual de $30 \%$.

\section{CONSIDERAÇÕES FINAIS}

A legislação procurou, por meio da implantação da logística reversa, resolver a problemática do destino das embalagens vazias de agrotóxicos, criando responsabilidades distribuídas e compartilhadas entre os membros integrantes dos elos da cadeia logística reversa.

O primeiro elo dessa cadeia está sob a iniciativa do produtor rural, aquele que utiliza os agrotóxicos em suas lavouras e que, segundo a legislação, deve iniciar o retorno das embalagens às industriais para o destino final adequado, entregando as embalagens ao revendedor ou aos postos de coleta por ele indicados.

Entretanto, a pesquisa deixou evidente que a tendência dos produtores rurais no município de Tupã-SP é de não cumprir totalmente o que determina a legislação. Embora a amostra não seja representativa, dá uma ideia geral de como procedem ou qual a intenção dos produtores rurais do município, eis que foram selecionados produtores grandes, médios e pequenos, com culturas diferenciadas e áreas também diferenciadas.

Como se demonstrou, torna-se evidente que $30 \%$ dos produtores têm a tendência de não cumprir a legislação, não dando início ao processo da logística reversa das embalagens vazias de agrotóxicos. Ainda, se for levado em consideração que 35\% deles são indiferentes, com tendência de poder ou não iniciar o processo, e aliando-se a isso as respostas à questão aberta "de quanto em quanto tempo devolve as embalagens", em que apenas dois produtores (10\%) afirmam categoricamente devolver, pode-se perceber forte tendência ao não cumprimento da legislação.

Essa tendência pode ser explicada em razão da falta de fiscalização, já que para a questão P-15 (Recebo com regularidade fiscalização sobre o armazenamento, transporte e devolução das embalagens vazias de defensivos agrícolas), registra-se que todos foram unânimes em afirmar que nunca receberam fiscalização. Daí a necessidade de maior empenho do Poder Público para cumprimento da legislação. 


\section{REFERÊNCIAS}

BOLDRIN, Vitor Paulo et al. A Gestão Ambiental e a Logística Reversa no Processo de Retorno de Embalagens de Agrotóxicos Vazias. RAI - Revista de Administração e Inovação, São Paulo, v. 4, n. 2, p. 29-48, 2007.

BRAGA JUNIOR, Sergio Silva; PINHEIRO, Luciane Ribeiro Dias. A importância da reciclagem dos resíduos sólidos dentro das organizações/The importance of recycling solid waste in organizations. Revista Brasileira de Engenharia de Biossistemas/Brazilian Journal of Biosystems Engineering, v. 7, n. 1, p. 55-69, 2014.

CANTOS, Clotilde; MIRANDA, Zoraide Amarante I.; LICCO, Eduardo Antonio. Contribuições para a Gestão das Embalagens Vazias de Agrotóxicos. INTERFACEHS - Revista de Gestão Integrada em Saúde do Trabalho e Meio Ambiente - v.3, n.2, Seção Interfacehs 1, abr./ agosto. 2008 www.interfacehs.sp.senac.br

CARBONI, Gleriani Torres; SATO, Geni Satiko; MOORI, Roberto Giro. Logística Reversa para Embalagens de Agrotóxicos no Brasil: Uma Visão sobre Conceitos e Práticas Operacionais. In: XLIII CONGRESSO DA SOBER "Instituições, Eficiência, Gestão e Contratos no Sistema Agroindustrial”. Ribeirão Preto, 24 a 27 de Julho de 2005.

COMETTI, José Luís Said. Logística reversa das embalagens de agrotóxicos no Brasil: um caminho sustentável? 2009. 152 f., il. Dissertação (Mestrado em Desenvolvimento Sustentável), Universidade de Brasília, 2009.

DA SILVA, Dirceu; LOPES, Evandro Luiz; JUNIOR, Sérgio Silva Braga. Pesquisa Quantitativa: Elementos, Paradigmas e Definições. Revista de Gestão e Secretariado, v. 5, n. 1, p. 01-18, 2014.

DEVELLIS, R. F. Scale development: theory and applications. Thousand Oaks: Sage Publications, 2003.

FARIA, Ana Cristina de; PEREIRA, Raquel da Silva. O Processo de Logística Reversa de Embalagens de Agrotóxicos: um estudo de caso sobre o INPEV. Organizações Rurais \& Agroindustriais, Lavras, v. 14, n. 1, p. 127-141, 2012

GAGEIRO, João Nunes; PESTANA, Maria Helena. Análise de dados para Ciências Sociais-A Complementaridade do SPSS. 2000.

GRUTZMACHER, Douglas Daniel et al. Embalagens Vazias de Agrotóxicos: organização dos fabricantes e suas obrigações (Lei Federal 9.974). R. Bras. Agrociência, Pelotas, v. 12, n. 1, p. 05-06, jan-mar, 2006.

HAIR, J. F.; BABIN, B.; MONEY, A. H. e SAMOEL, P. Fundamentos de Métodos de Pesquisa em Administração. Porto Alegre: Bookman, 2005.

HAIR, Joseph F. et al. Análise multivariada de dados. Bookman, 2009.

IBGE, Produção Agrícola Municipal 2013. Rio de Janeiro: IBGE, 2014.

INPEV - INSTITUTO NACIONAL DE PROCESSAMENTO DE EMBALAGENS VAZIAS. Estatísticas do setor. Disponível em: <www.inpev.org. br/educacao/noticias/br/noticias.asp>. Acesso em: 30 jun. 2015.

JUNIOR, Sergio Silva Braga; MERLO, Edgard Monforte; NAGAN, Marcelo Seido. Um estudo comparativo das práticas de logística reversa no varejo de médio porte. Revista da Micro e Pequena Empresa, v. 3, n. 2, p. 64 81, 2011.

LEITE, Paulo Roberto. Logística Reversa: meio ambiente e competitividade. São Paulo: Prentice Hall, 2003. 
MARQUES, Maurício Dias; BRAGA JUNIOR, Sérgio Silva; CATANEO, Pedro Fernando. Discussão da estrutura formal sobre o retorno das embalagens de agrotóxicos: uma revisão teórica sob os aspectos legais e da consciência ambiental. Periódico Eletrônico Fórum Ambiental da Alta Paulista, XI Fórum Ambiental da Alta Paulista, v. 11, n. 2, 2015, pp. 30-56.

MELO, Wederson Miranda et al. Logística Reversa de Embalagens de Agrotóxicos: um estudo de caso na cidade de Patos-MG. In: Congresso Nacional de Excelência em Gestão, VIII, 2012, Niterói . Anais..., Rio de Janeiro.

MOTTA, Wladmir Henriques. Análise do Ciclo de Vida e Logística Reversa. In: SEGeT Simpósio de Excelência em Gestão e Tecnologia, X, 2013, Resende. Anais..., Rio de Janeiro.

MOURÃO, Renata Fernandes; SEO, Emília Satoshi Miyamaru. Logística reversa de lâmpadas fluorescentes. InterfacEHS Revista de Saúde, Meio Ambiente e Sustentabilidade. V. 7, N. 3, 2012

ORGANIZAÇÃO PAN-AMERICANA DA SAÚDE / ORGANIZAÇÃO MUNDIAL DA SAÚDE (OPAS/OMS). Manual de Vigilância da Saúde de Populações Expostas a Agrotóxicos. Disponível em: < http://bvsms.saude.gov.br/bvs/publicacoes/livro2.pdf>. Acesso em: 01 jul. 2015.

PESTANA, M. H. e GAGEIRO, J. N. Análise de Dados para Ciências Sociais: A Complementaridade do SPSS. $2^{\circ}$ ed. Lisboa: Edições Silabo, 2000.

SHIBAO, Fábio Ytoshi; MOORI, Roberto Giro; SANTOS, Mário Roberto dos. A logística reversa e as embalagens vazias de defensivos agrícolas no Brasil. In: SIMPÓSIO DE ENGENHARIA DE PRODUÇÃO, XVIII, 2010, Bauru. Anais..., São Paulo.

TEDESCO, J. C. (Org). Agricultura familiar: realidades e perspectivas. Passo Fundo: UPF, 2001.

VICTOR, P.T. Opiniao - Politica Nacional dos Residuos Solidos. Noticias Financieras, Miami Aug 24, 2010. 